Volume 7 - No 2 - Maio/Agosto de 2013

\title{
O game CityVille: uma nova tendência da Web
}

\author{
Patrícia Margarida Farias COELHO \\ Pós-doutoranda TIDD/PUC-SP \\ Bolsista FAPESP \\ patriciafariascoelho@gmail.com
}

\author{
Ruth S. Contreras Espinosa \\ Grup de Recerca Interacciones Digitals \\ Universitat de Vic (España) \\ ruth.contreras@uvic.cat \\ Irene García Medina \\ Grup de Recerca Interaciones Digitals \\ Universitat de Vic (España) \\ iregarcia@gmail.com
}

\section{Resumo}

O objetivo principal desse artigo é analisar o jogo social CityVille criado pela empresa Zynga, uma das últimas tendências do Facebook encontrado e disponível na web. A escolha do corpus game CityVille deve-se ao interesse de buscar compreender o por que esse jogo obteve tamanho sucesso e seja atualmente um dos jogos sociais/digitais de maior destaque e adeptos da rede social Facebook. Busca-se dessa maneira depreender de que maneira os jogos sociais tem evoluído e transformado as relações comunicacionais entre os usuários da rede. As redes sociais têm se tornando cada vez mais importantes e estão vinculadas a vida das pessoas. Com o desenvolvimento da linguagem digital, a forma com que as pessoas passaram a interagir se transforma, pois essas se comunicam através do computador em tempo real. O estudo busca fazer uma análise plural do jogo CityVille destacando distintos pontos de vista do jogo social. Propomos verificar as relações entre: o uso e os usuários, e a tecnologia e o conteúdo do jogo. Nas 
EDUCAONLINE

ISSN $1983-2664$

\title{
Volume 7 - No 2 - Maio/Agosto de 2013
}

conclusões explicitaremos quais serão as direções possíveis do futuro dos jogos sociais da web.

Palavras-chave: jogos sociais; redes sociais on line; tendências; facebook.

\section{The City Ville Game: A New Trend on the Web}

\begin{abstract}
The main aim of this article is to analyze the social game CityVille created by the company Zynga. The game is one of the most recent trends of Facebook available in the web. The election of the game CityVille is to understand the reasons for the huge success obtained by the game. Also, it will be interesting to understand the way that social games has evolved and transformed the communicational relations between the users of the net. Social networks are becoming more and more important and today they are part of the peoples' lives. With the development of digital language, the way people communicate is changing, now it is possible to communicate with other people through the computer in real time. This study realizes a plural analysis of the game CityVille analyzing different points of view of the social game. The relations between the use of the game and the users, and between the technology and the content of the game are analyzed. In the conclusions we will show the possible directions of the future of social games in the web.
\end{abstract}

Keywords: social games, on line social networks; trends; facebook.

As pessoas criam comunidades nas redes com a mesma inevitabilidade com que microorganismos criam colônias.

Howard Rheingold

\section{Introdução}

Atualmente vivemos um momento de transformações com o desenvolvimento da internet. Depois do surgimento da web 2.0 nada mais pode ser pensando como 


\section{Volume 7 - No 2 - Maio/Agosto de 2013}

antes: mídias, educação, publicidade, dentre outros. As indústrias desenvolvedoras de games atentas a proliferação dos jogos digitais on line tem dedicado-se ao desenvolvimento de tecnologias para a cada dia inovaram seus hardware e software e assim deixarem seus videogames mais interessantes aos jogadoresconsumidores. Os jogos digitais encontram-se em tamanha expansão que hoje encontram-se facilmente nas redes sociais em distintas plataformas. É evidente que o jogador-consumidor já acostumou-se a entrar na rede e encontrar os seus games preferidos associados a alguma plataforma. $O$ jogo digital transformou-se em um dos serviços de entretenimento de maior sucesso dessas redes sociais.

Neste artigo escolhemos como corpus o game CityVille encontrado no Facebook. Esse jogo foi escolhido por ter alcançado em apenas um mês depois de seu lançamento a quantidade de 84.2 milhões de jogadores (Caoili, 2011), convertendo- se assim no jogo mais ativo que Facebook já teve.

Ao nos conectarmos em nosso perfil no Facebook encontrarmos em nossa página mensagens sobre o progresso de nossos amigos, bem como sua solicitação com pedidos de ajuda ou de envio de presentes. Verifica-se que a cada dia mais e mais pessoas colaboram e participam dos jogos virtuais disponives nas redes sociais. De acordo com informações da Parks Associates (Europa Press, 2011), mais de 250 milhões de pessoas desfrutam atualmente dos jogos sociais, e em 2015, os jogos sociais podem chegar a facturar 3.464 milhões de euros.

De Vasconcelos Guimarães (2008, p. 30-31) explica que os games são:

Uma experiência sensorial e sinestésica que afeta diretamente os sentidos, os sentimentos e o raciocínio através de uma programação eletrônica e/ou digital interativa. Ou seja, um game precisa ser entretenimento. Dentro dessa proposta, um game tem diversos elementos que o formam. $E$ são esses elementos que o fazem efetivamente, algo diferenciado de um filme ou um livro, uma peça de teatro, um programa de televisão ou uma história em quadrinhos. Mesmo que o game compartilhe muito desses elementos com as 


\section{REVISTA}

\section{Volume 7 - No 2 - Maio/Agosto de 2013}

mídias supracitadas, ele tem algo que diferencia fundamentalmente: a interação do jogador como ação direta e casual no fluxo do game.

Neste artigo temos o objetivo de compreender o game enquanto um jogo social criado para uma plataforma on line. Portanto em nosso estudo estamos nos debruçando sobre jogos sociais que devem ser entendidos como: casuais, digitais e estarem veiculados dentro de uma rede social como é o caso do City Ville corpus de nossa pesquisa. De acordo com Juul (2010) os "Jogos sociais, bem como suas funções públicas são uma vitrine já que se encontram nos jogos casuais". Ambos os tipos de jogos fazem parte dos produtos como uma modalidade de negócio que permitem aos jogadores acesso aos jogos on-line sem a necessidade de instalar software ou até mesmo a partir de qualquer dispositivo móvel com acesso à rede. $A$ facilidade de acesso a esses jogos digitais e sem dúvida um dos principais destaques para sua propagação. Se compararmos o City Ville com os jogos que são vendidos para computadores, consoles e até mesmo aqueles identificados como jogos multiplayer (Massive Multiplayer Online Role Playing Game) observaremos que os games on line ainda são pouco estudados e quase não tem pesquisas sobre esses novos jogos disponiveis nas plataformas de as redes sociais.

A obra Homo Ludens, de Huizinga, explicita que somente há jogo quando o jogador passa por quatro etapas, tais etapas são descritas pelo autor seguindo a seguinte ordem: primeiro o jogador deve querer jogar - voluntariedade. A segunda etapa é tempo, uma vez que, o jogo não faz parte da nossa vida comum e, simboliza uma fuga temporária da realidade. A limitação no tempo e no espaço é o terceiro item, pois o jogo é estabelecido a partir de um tempo e um espaço limitado. E o quarto item é ordem. Para Caillois (1991), o jogo é uma atividade que é essencialmente livre, voluntária, separada no tempo e no espaço, incerta, improdutiva, governada pelas regras da fantasia. Verificamos, portanto, que ambos os autores, Huizinga e Caillois, definem cada um a sua maneira praticamente as mesmas coisas para explicar o conceito do jogo. Podemos ainda acrescentar as palavras de Järvinen (2010), a fim de esclarecer o conceito do jogo social: "São 


\section{Volume 7 - No 2 - Maio/Agosto de 2013}

jogos on line que servem para as amizades virtuais em jogo, enquanto se adapta à rotina diária."

Deterding (2010) explica que os jogos sociais não são realmente sociais, pois os jogos sociais que estão agora no Facebook, apresentam uma interação síncrona entre os jogadores que se ajudam mutuamente para que ambos possam crescer. Verifica-se, portanto, que os jogadores precisam estar conectados e convidar amigos para que sua cidade cresça, como é o caso de CityVille.

A interaçao é realizada com objetos ou existe uma interacão onde os jogadores são usados como testemunhas, porque não existe uma interação direta com outros jogadores, como pode acontecer num jogo de console, por exemplo, e é o tamanho da rede social o que proporciona o impulso na actividade do jogo e não a habilidade do jogador. Ainda, Deterding diz que existe pouca mecânica social, ja que os jogos não usam mecanismos para facilitar as interações entre os jogadores e não incentivam que os jogos sejam cooperativos. Ainda asim, é razoável considerar que uma interação assíncrona é outro tipo de relação social motivada pelos esquemas sociais das propias redes virtuais, onde o trabalho é feito de maneira assíncrona.

Os jogos sociais encontrados nas redes sociais começam a ser objeto de interesse e estudo de pesquisadores do mundo todo. Os jogos sociais são uma inovação e começam a transformar o desenvolvimento dos padrões dos games, da distribuição e de negócios da indústria de jogos. Ao mesmo tempo, que novas questões se levantam a respeito dos jogos como: compreender por que esses jogos são tão atraentes para os usuários que anteriormente não eram jogadores e verificar quais são as suas motivações para seu uso.

A pesquisa sobre o game City Ville ainda encontra-se em desenvolvimento e observação uma vez que o jogo foi criado nesse ano (2011) e é recente sua disponibilidade na plataforma do Facebook. $O$ artigo pretende ser uma reflexão inicial sobre a criação, desenvolvimento e evolução dos jogos digitais. Este estudo apresenta-se como uma primeira tentativa de organizar a investigação existente em 
EDUCAONLINE

ISSN 1983-2664

\section{Volume 7 - No 2 - Maio/Agosto de 2013}

jogos sociais através da análise do game City Ville depreendendo como um produto que representa a tendência mais recente na rede.

\section{City Ville e suas características narrativas interativas e participativas}

O game CityVille encontrado na web (Facebook) é para os publicitários um novo tipo de mídia que apresenta características próprias que emergiram com o desenvolvimento da internet. A principal diferença desse game on line esta na maneira com que este se relaciona com o jogador(a). $O$ jogo social apresenta uma inovação narrativa que é aberta e não linear.

Murray (2003) nomeia esse novo tipo de narrativa de multissequêncial. No game CityVille encontramos desse tipo de narrativa multissequencial, pois ela oferece ao jogador a possibilidade deste criar uma cidade.

Os jogos sociais permitem um novo tipo de interação participativa na narrativa que antes não foi possível de se realizar. A narrativa do game CityVille deve portanto ser classificada como uma narrativa participativa, uma vez que, a mesma só se realizará através das ações do jogador(a), e colaborativa, pois os jogadores precisam da ajuda dos amigos do Facebook para que sua cidade se desenvolva.

Jenkins (2009) e Murray (2003) destacam sobre a urgência de se pensar o meio digital a partir de novos conceitos uma vez que o meio apresenta características novas e que devem ser entendidas a partir de uma nova perspectiva teórica. Os games sociais são novas formas de comunicação que se estabelecem através de novas estratégias midiáticas. (Murray, 2003) destaca que:

Quanto mais convincente for o meio, mais perigoso ele é. Tão logo nos abríamos a esses ambientes ilusórios que são "tão reais quanto o mundo", ou até "mais reais que a realidade", abandonamos nossa razão e nos misturamos às massas indistintas para servilmente nos conectar a máquinas de estimulação, ao custo de nossa própria humanidade. 


\section{REVISTA}

EDUCAONLINE

ISSN 1983-2664

EDUCOMUNICACÃO

EDUCOMUNICACÃO
OVAS TECNOLOGIAS

(latec) UFW

\section{Volume 7 - No 2 - Maio/Agosto de 2013}

Verifica-se, portanto, que os games oferecem a possibilidade de satisfazer nossos desejos e nos permitir ter a ilusão de ampliar nossas habilidades uma vez que nossas vitórias não são somente vistas pelo jogador-vencedor, mas também pelos seus amigos-jogadores que testemunham sua competência no desenvolvimento do jogo. O jogador ao ajudar um amigo ou oferecer suporte para ampliar sua cidade no CityVille (mundo virtual) não só reforça as relações sociais, mas ajuda o usuário a sentir-se poderoso, uma espécie de Deus.

O game CityVille tem duas características-chave que possibilitam seu sucesso: primeiro estão integrados em um espaço social, que permite aos jogadores jogar com os amigos que conhece na vida real ou com jogadores (amigos virtuais) que estabeleceram uma relação on line e segundo porque ele tem um lugar único no ecossistema do jogo, pois possibilita a interação social e é fácil de se utilizar devido a plataforma que se encontra e a tecnologia que utilizam.

Kirman (2010) em suas pesquisas identifica que há quatro arquéotipos do jogo social que são classificados em relação à interação social entre os usuários: a) Os jogadores usuais evangelistas que começam as relações sociais; b) jogadores sociais casuais cujas as interações estão geralmente ligadas a um pequeno grupo de contatos; c) Os recrutas que raramente iniciam a relação mas que sempre correspondem às interações; d) Anti-Social nunca inicia uma relação ou dá reciprocidade à interação.

Já Wohn (2010) em seus estudos classifica algumas aplicações paralelas que são dadas aos jogos sociais da seguinte maneira: a) um espaço comum, pois os jogos são usados para construir temas e experiências que proporcionam uma base para a realização de interações de fora do jogo; b) reciprocidade, atividades que resultam em ajudar para ser ajudado; c) abordar situações o uso de jogos sociais para lidar com situações que estão fora do jogo; d) a passagem do tempo, jogar e deixar as horas passar.

Observa-se que o maior atrativo para os jogadores-usuários do jogo CityVille é a facilididade de construir sua cidade, ou seja, possibilidade de imersão e de 


\section{Volume 7 - No 2 - Maio/Agosto de 2013}

sentir-se momentaneamente um Deus. Pretendemos através da análise do game CityVille compreender as novas formas de relação que surgem no século $X X I$. $O$ Facebook é a rede social que possibilitou novas formas de relações entre os amigos e apresenta-se como uma plataforma que permite que os amigos estendam suas formas de interagir e relacionar-se através de seus jogos sociais.

\section{Os usuários e suas novas relações nas plataformas digitais}

O Orkut, Twitter, Facebook dentre outros são exemplos de novas plataformas comunicacionais que surgiram com o desenvolvimento da internet. Tais plataformas são conhecidas como redes sociais e hoje essas passaram a serem indissociáveis da vida de muitos usuários da web. Atualmente a maior parte das relações entre as pessoas se estabelecem através e a partir da internet e das redes sociais. $O$ universo digital permite que os indivíduos se comuniquem através do computador em tempo real mudando assim as formas de comunicação.

Com o desenvolvimento dos avanços tecnologicos podemos atualmente jogar em e com distintos aparatos como smartphones, navegadores web e consoles. Porém sem dúvida a maior mudança se matrealiza e concretiza na hibridização do jogo com a rede social. De acordo com as pesquisas do social gaming, realizadas nos EUA e na Grã-Bretanha pela empresa PopcapGame (2010), 55\% dos jogadores sociais são mulheres, idade média 43 anos. Nos EUA, $46 \%$ dos jogadores tem mais de 50 anos e apenas $6 \%$ são menores de 21 anos. E você pode ver que $95 \%$ dos entrevistados joga várias vezes por semana, em 59\% dos casos jogam 30 minutos por dia. Mais de $56 \%$ vem jogando há mais de um ano e $83 \%$ o fazem através de Facebook, enquanto $62 \%$ das pessoas preferem interagir somente com seus amigos.

O CityVille utliza-se da fórmula freemium que consiste em atrair clientes com um produto gratuito, no nosso caso o jogo digital e, a partir daí oferecer ao jogador a possibilidade de comprar bens virtuais com dinheiro real. Dessa maneira o jogador passa a ter a possibilidade de ampliar sua cidade mais rapidamente. 
EDUCAONLINE

ISSN 1983-2664

\section{Volume 7 - No 2 - Maio/Agosto de 2013}

A tendência de oferecer através dos jogos sociais a possibilidade de compras virtuais caracteriza-se como um modelo de negócio que garante a rentabilidade e o lucro das empresas desenvolvedoras de games. A empresa Zynga criadora do jogo digital CityVille utiliza-se do recurso de oferecer ao jogador-consumidor a possibilidade de acelerar o desenvolvimento de sua construção caso compre algumas vantagens com seu cartão de crédito. Na Europa, a taxa de penetração do modelo F2P total para jogos on-line é de $80 \%$, deixando $20 \%$ para o modelo de negócio de jogos para pagar pelo acesso ou Pay to Play. O F2P tem uma massa estimada de usuários em mais de 30 milhões de pessoas em toda a Europa (ONTSI, 2010).

Verifica-se que as empresas desenvolvedoras de jogos digitais aproveitam-se dos valores almejados pelos jogadores de poderem se divertir, aproveitar a vida e satisfazer seus desejos em ambientes nos quais podem e passam a ser sentirem valorizados e importantes.

\section{Os novos caminhos e mercados da tecnologia}

CityVille aproveita-se da plataforma digital Facebook que permite aos usuários entrarem no jogo e utilizarem-se desse ambiente social como uma técnica de viral (Järvinen, 2010) para sua distribuição. O que se observa é que os jogos podem se desenvolver em diferentes espaços e plataformas de interação para além das plataformas que conhecemos.

Bogost (2007) explica que mesmo que as ações de um game tenham previsto distintas ações do usuário no ato de sua criação haverá um momento em que o jogador fará uma escolha que não havia sido prevista no ato da criação do game. Lemos (2009) compartilha desse raciocínio reiterando que esse meio é "uma potência para criação de linhas de fuga" que nunca foram imaginadas no seu desenvolvimento. 


\section{REVISTA}

EDUCAONLINE

ISSN 1983-2664

EDUCOMUNICACÃO

EDUCOMUNICACÃO
OVAS TECNOLOGIAS

(latec) UFW

\section{Volume 7 - No 2 - Maio/Agosto de 2013}

Para que um jogo digital tenha sucesso na rede social é necessário que ele esteja em uma plataforma conhecida, tenha uma narrativa envolvente (conteúdo) e seja de fácil distribuição. Se qualquer um desses pilares é fraco ou inexistente, o potencial de jogo e produtos virtuais não se materializam. Arrington (2009) pontua que os jogos sociais são observados até mesmo como um objeto de difamação para o designer do jogo profissional.

Paavilainen (2010) explica que se projetar os games esses devem ter como principal característica apelar para o maior audiência possível. A estratégia criativa deve se concentrar no desenvolvimento de um portfolio que represente a melhor opção para os usuários, isto é, o jogo deve ter um conteúdo informal com um baixo grau de dificuldade e que apresentem temas fáceis e divertidos (Lazzaro 2008).

No CityVille verificamos que os jogadores-usuários do Facebook estão entretidos em convidar o maior número de amigos para ajudá-lo a ampliar sua cidade. O jogador ao começar a construir de sua cidade deve convidar os amigos para que sua cidade possa tornar-se uma metrópole. O jogador a cada dia que participa do jogo irá obtendo vantagens e sua cidade vá aumentando. Porém observa que o objetivo do Facebook ao disponibilizar um game em sua plataforma é fazer com que o jogador-usuário permaneça mais tempo em sua rede social e para isso utiliza-se de links com entretenimento e possibilidades de compras como já visto acima.

Juul (2010) explicita que a interruptibilidade em um jogo é um elemento facilitador para seu uso e para a retenção dos jogadores. Björk (2010) menciona que o tempo faz um jogo baseado em pulsos, ou seja, o tempo de jogo avança em tempo real mas discretamente, e por sua vez permite um jogo assíncrono.

O jogo CityVille oferece cidades virtuais e a mecânica do game consiste em realizar tarefas repetitivas para poder ampliar a cidade. A ação repetida acaba por desenvolver um vinculo emocional que ajuda a fazer com que o usuário-jogador permaneça no jogo. Por outro lado, a interação repetida fornece uma parte fundamental do modelo de negócio já que introduz deliberadamente intervalos entre 
EDUCAONLINE

ISSN 1983-2664

EDUCOMUNICACÃO

EDUCOMUNICACÃO
NOVAS TECNOLOGIAS

(latec) UFW

\section{Volume 7 - No 2 - Maio/Agosto de 2013}

cada um dos níveis ou atividades de jogo, pois estimula o usuário a realizar micro transações monetárias. Em um modelo de negócio freemium todas as mecânicas do jogo são mecânicas de retenção que indicam um caminho para monetização, estabelecimento metas o que significa que o jogador é direcionado para encontrar dificuldades e obstáculos e assim torna-se mais fácil que esse realize um pagamento através da compra de algum tipo de vantagem ou produto virtual a fim de tornar ver-se livre das dificuldades que Ihe foram apresentadas no jogo (Järvinen, 2010 ).

\section{Considerações Finais}

Este artigo buscou compreender o novo game social CityVille do Facebook. Ele foi selecionado para formar parte do corpus por encontrar-se na rede social e ter alcançado o número de 84 milhões de usuários por mês logo após dois meses de seu lançamento. O jogo social oferece ao jogador uma narrativa aberta - construir uma cidade e dependerá das ações jogador para que seu mundo virtual cresça, porém, esse necessita das ações de outros colegas para colaborar no desenvolvimento de sua cidade.

Com os avanços da internet alteraram-se as formas de comunicação e consequentemente também se ampliaram as possibilidades de se jogar. Hoje podemos jogar em qualquer lugar, sozinhos ou em grupos e nossa interação com o jogo continua a evoluir. Com os desenvolvimentos das redes sociais, essas plataformas com seus jogos de entretenimento passaram a fazer parte de nossas vidas e de nossas experiências diárias. Os usuários da web e em especial do Faceobook têm provado que o game CityVille é uma atividade de entretenimento de sucesso, pois muitos usuários dedicam uma boa parte do seu tempo no jogo.

O CityVille caracteriza como um jogo social que é definido como um game on line que possui duas características fundamentais para fazer parte das tendências da web: são integrados em um espaço social que permite aos jogadores interagir e 
EDUCAONLINE

ISSN 1983-2664

\section{Volume 7 - No 2 - Maio/Agosto de 2013}

com um lugar único no ecossistema dos jogo por ser produtos fáceis de desenvolver produtos pelas empresas.

Verificou-se no desenvolver dessa pesquisa que os jogos sociais têm afetado e transformado as relações comunicacionais entre os usuários da rede. O jogador através das suas escolhas estará criando visualmente e espacialmente através das figuras de que maneira sua cidade se apresentará para si e para seus colegas. Mas o desenvolvimento de sua cidade ocorre de forma colaborativa e participativa, portanto, a ajuda dos amigos do Facebook é indispensável no mundo digital.

Os jogos sociais ainda se encontram em fase de definição e propagação. Através dessa pesquisa acredita-se que, se os jogos continuarem se desenvolvendo da maneira como estão, se consolidarão como uma das partes mais importantes da indústria desenvolvedoras de videogames. Apesar de serem considerados jogos menores por um grande número de usuários e empresas de jogos tradicionais de vídeo. A quantidade de adeptos do CityVille que alcançou o número de 84 milhões de usuários logo após dois meses de seu lançamento tem explicitado a força que esses jogos digitais/sociais têm no mercado mundial. Portanto hoje quando alguém menciona jogo de computador está referindo-se especificamente aos jogos sociais do tipo do CityVille que encontram-se disponível em alguma das plataformas da web. Acreditamos que as redes sociais em breve serão integradas em sistemas operacionais que estão sendo criados na web (cloud computing) o que fará com que os jogos não façam parte de um navegador.

Pode-se pensar em tecnologias avançadas para jogos sociais. Os usuários dos jogos digitais/sociais costumam pontuar que ele deveria evoluir para a realidade virtual, 3D e novas interfaces, sem controles e capaz de estimular os cinco sentidos (ADESE, 2011). 
Volume 7 - № 2 - Maio/Agosto de 2013

\section{Referências Bibliográficas}

ADESE (Asociación Española de Distribuidores y Editores de Software de Entretenimiento). Estilos de vida y valores de los jugadores de videojuegos españoles. Primer semestre de 2011. http://www.adese.es/index.php?option=com_content\&view=article\&id=10\&ltemid=6 Acesso em 1/11/2011.

ARRINGTON, Michael. Scamville: Zynga Says 1/3 Of Revenue Comes From Lead Gen And Other Offers. TechCrunch. http://techcrunch.com/2009/11/02/scamvillezynga-says-13-of-revenue-comes-from-lead-gen-and-other-offers. Acesso em 2/11/2011.

BOGOST, lan. Persuasive Games. The expressive power of videogames. London: The MIT Press, 2007.

BJORK, Staffan. Principles and patterns of social games: Where's the difference compared toother games?. En: Games Convention Online, 7-10-2010. Acesso em 2/11/2011.

CAILLOIS, Roger. Les jeux et les hommes. Paris: Gallimard Editions, 1991.

CAOILI, Eric. CityVille has largest Facebook Audience Ever. 2-01-2011. Gamasutra. http://www.gamasutra.com/view/news/32231/CityVille_Has_Largest_Facebook_Audi ence_Ever.php?utm_source=feedburner\&utm_medium=feed\&utm_campaign=Feed: +GamasutraNews+(Gamasutra+News)\&utm_content=Google+Reader Acesso em 30/10/2011.

DETERDING, Sebastian. Social Game Studies: A Workshop Report. Hans Bredow Institute for Media Research. 2010. http://socialgamestudies.org/report. Acesso em 2/11/2011.

EUROPA PRESS. Los juegos sociales facturarán casi 3.500 millones anuales en 2015. Madrid, 11-04-2011. PortalTic. 
EDUCAONLINE

ISSN 1983-2664

\section{Volume 7 - No 2 - Maio/Agosto de 2013}

http:/www.europapress.es/portaltic/internet/noticia-juegos-sociales-facturaran-casi3500-millones-anuales-2015-20110411155006.html. Acesso em 3/11/2011.

GUIMARÃES, Daniel de Vasconcelos. O campo de referências dos videogames: estudo semiótico sobre o objeto dinâmico do game. Dissertação de mestrado. São Paulo: Pontifícia Universidade Católica de São Paulo, 2008.

HUIZINGA, Johan. Homo ludens: O jogo como elemento da cultura. São Paulo: Perspectiva, 2001.

JARVINEN, Aki. The Quest for Aesthetics in a Metrics-driven Business. En: Games Convention Online, 2010.

JENKINS, Henry. Cultura da Convergência. Tradução: Susana Alexandria. 2. ed. Amp. e atual.São Paulo: Aleph, 2009.

JUUL, Jesper. A Casual Revolution: Reinventing Video Games and Their Players. Cambridge: MIT Press, 2010

KIRMAN, Ben. Playful Clusters: Motivations and Social Structures in Social Games. En: Games Convention Online, 2010.

LAZZARO, Nicole. Why We Play: Affect and the Fun of Games. Designing Emotions for Games, Entertainment Interfaces and Interactive Products. En: Sears, Andrew y Jacko, Julie. The Human-Computer Interaction Handbook. Fundamentals, evolving technologies and emergingapplications. New York: Lawrence Erlbaum, 2011, pp. 155-176.

LEMOS, André. Nova esfera conversacional, En: KUNSCH, Dimas. et al. Esfera pública, redes e jornalismo. Rio de Janeiro: E-Papers, 2009, pp. 9-30.

MURRAY, Janet. Hamlet no Holodeck. O futuro da narrativa no ciberespaço. Tradução; Elissa Khoury Daher e Marcelo Fernandez Cuzziol. São Paulo: Itaú Cultural; Unesp, 2003.

ONTSI. Informe Anual de los Contenidos Digitales en España 2010. Gobierno de España. 
EDUCAONLINE

\section{Volume 7 - No 2 - Maio/Agosto de 2013}

http://www.ontsi.red.es/articles/detail.action?id=4963\&request_locale=es Acesso em 15/09/2011.

PAAVILAINEN, Janne. Users and Their Experiences in Social Games. En: Games Convention Online, 2010.

POPCAPGAME. Social Gaming Research 2010. Information Solutions Group. http://www.infosolutionsgroup.com/2010_PopCap_Social_Gaming_Research_Result s.pdf. Acesso em 8/11/2011.

WOHN, Donghee, Lee, Yu-Hao, Sung, Jieun, \& Bjornrud, Torger. Building common ground and reciprocity through social network games. En: CHI'10 Proceedings 28th international conference on Human factors in computing systems, 2010, pp. 44234428.

\section{Sobre as Autoras}

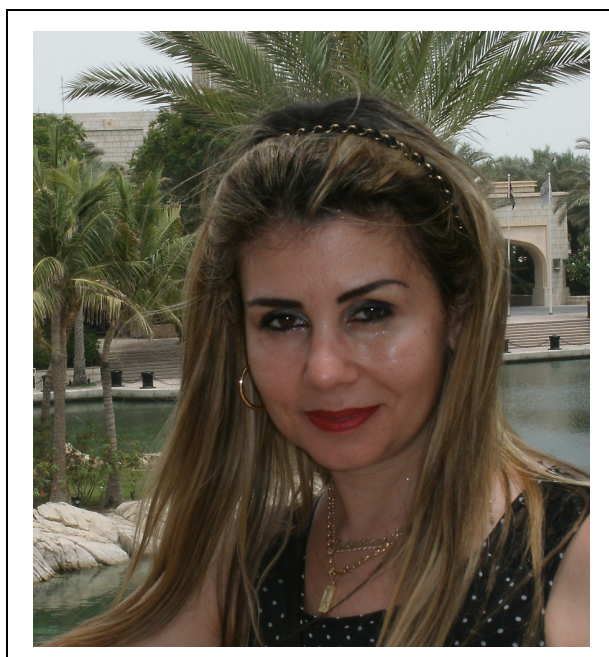

\section{Patricia Margarida Farias Coelho}

Mestre em Letras pela Universidade Presbiteriana Mackenzie e Doutora em Comunicação e Semiótica pela Pontifícia Universidade Católica de São Paulo desde 2010. Atualmente faz PósDoutorado no Programa de Pós-Graduação em Tecnologias da Inteligência e Design Digital da PUC-SP sob a supervisão de Maria Lúcia Santaella Braga e co-supervisão de Waldir Beividas da USP Durante um período de seu PósDoutorado atuou como professora visitante na Universidade de VIC - Espanha. 


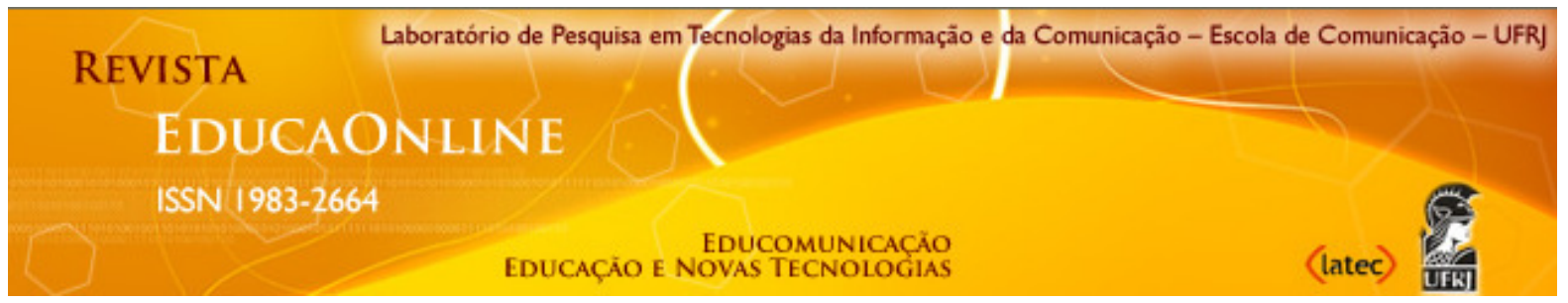

\section{Volume 7 - No 2 - Maio/Agosto de 2013}

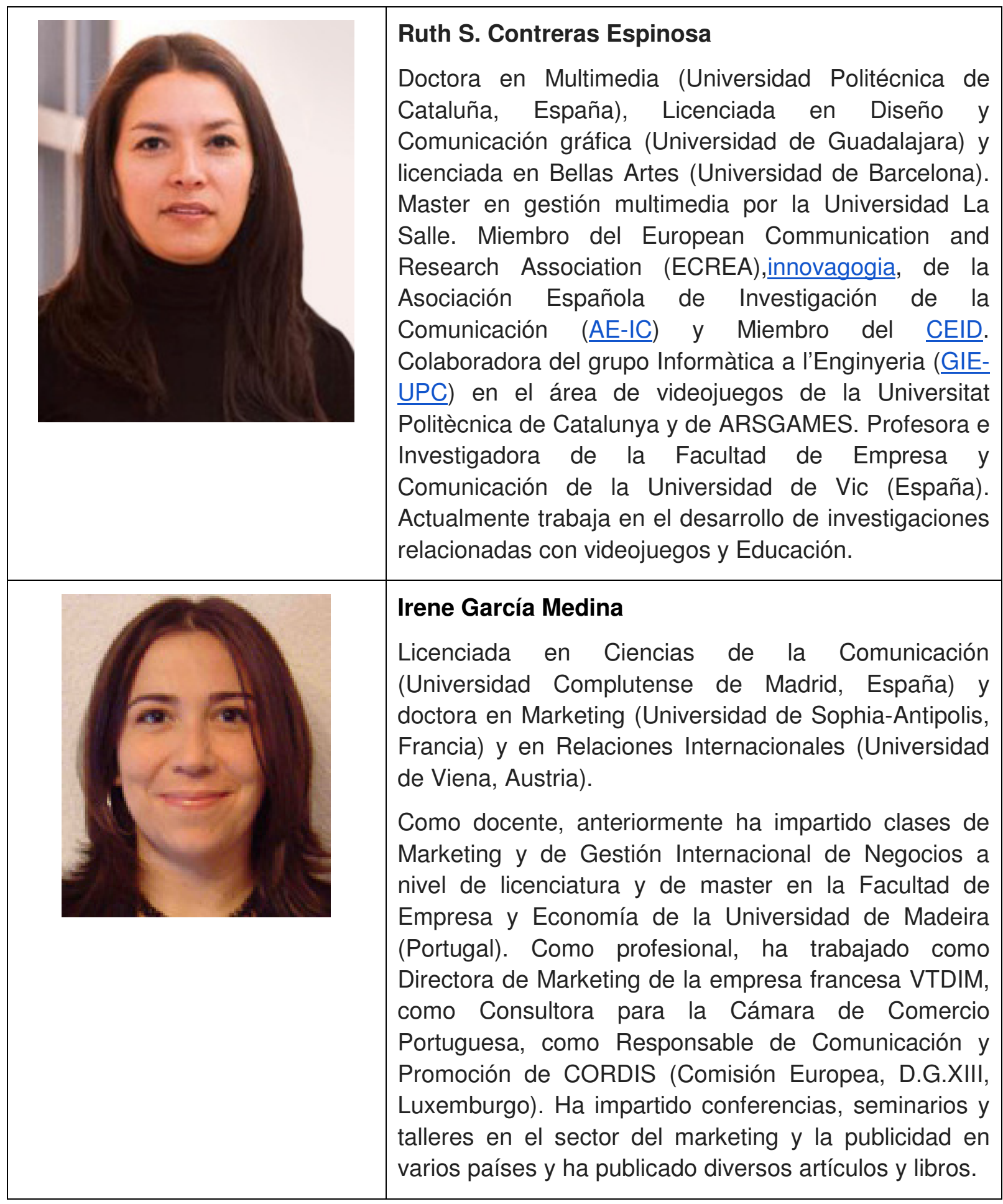

Revista EducaOnline, Volume 7, $\mathrm{N}^{\circ}$ 2, Maio/Agosto de 2013. ISSN: 1983-2664. Este artigo foi submetido para avaliação em 2/3/2013 e aprovado para publicação em 11/05/2013. 